\title{
La cátedra abierta y permanente de Ética
}

\section{Anamaría Caballero Páez}

La Cátedra Abierta y Permanente de Ética se propuso como un espacio de discusión y reflexión ético-política para debatir las diferentes corrientes del pensamiento axiológico y político, que propicie la resignificación de las representaciones culturales y sociales de sentido que permitan desarrollar una mirada socio histórica sobre las relaciones entre educación, ética y cultura colombiana, de tal manera que los estudiantes de la Universidad Pedagógica Nacional asuman una conciencia clara de su función como actores sociales en la construcción de la sociedad civil, la democracia, la promoción y la defensa de los derechos humanos, el crecimiento económico y el desarrollo social. La formación de valores morales que fundamenten una ética cívica parte del conocimiento de la realidad nacional y global, de la autoconciencia de cada individuo que aspira a constituirse en un ser autónomo usando su pensamiento crítico y participando en la construcción de la democracia, como modelo de gobierno que garantiza las libertades individuales, propiciando espacios para la conquista de los ideales de libertad, equidad, solidaridad y tolerancia, que permitan la convivencia ciudadana y la construcción de la nacionalidad colombiana.

Palabras clave: Educación, ética, cultura, sociedad, democracia, valores morales, derechos humanos, civilidad, trabajo, autonomía, libertad.

\section{Contexto}

Para Colombia, enfrentada al estallido violento de una crisis larvada durante toda su historia, definiendo con dificultad los caminos a seguir, es definitivo acceder a lo que se ha ido convirtiendo en un proyecto implícito y explicito de nuestra sociedad: la civilidad, el respeto a la multiculturalidad y los derechos humanos; el crecimiento económico y el desarrollo social. Ahora bien, no hay fórmulas aplicables a todas las circunstancias. Sólo existe la posibilidad de formar las mentalidades en estos valores, y para ello, es necesaria una cuidadosa formación, que permita el conocimiento y la deliberación, la discusión y la asunción de criterios, el rigor y la autonomía individual.

Por tanto, la orientación de la Universidad Pedagógica Nacional debe corresponder a las expectativas de vida y de trabajo del país real, de tal modo que haga de los nuevos profesionales, miembros activos de la sociedad. El ideal es que, tanto el estudiante, como la comunidad académica, en general, adquieran un profundo compromiso social y democrático, que se debe reflejar en su postura general ante el mundo, ante el trabajo y ante el otro.

Por ello, durante el primer semestre del 2001 funcionó la Cátedra Abierta y Permanente de Ética, como proyecto prioritario de extensión de la Facultad de Educación Física, la cual brindó una perspectiva social, en la medida en que permitió reflexionar en torno a algunas preguntas como: ¿cuáles son los valores que debe representar el estudiante y futuro maestro?, ¿cuál su compromiso frente al trabajo?, ¿cuáles sus actitudes frente a la ciencia, al otro, a la diversidad cultural, a los derechos humanos?, ¿cuál es su participación en la vida social y por ende en la construcción de la civilidad?

\footnotetext{
* Profesora de la Facultad de Educación Física, Universidad Pedagógica Nacional 


\section{La ética: una filosofía de vida}

La formación de valores morales y civiles parte del conocimiento de la realidad nacional, del reordenamiento territorial, de la política regional y local, y del reconocimiento de la diversidad étnica y cultural, para educar en la tolerancia y los derechos humanos, y hace ver la necesidad de una democracia efectiva, en la cual se tengan en cuenta el valor y la dignidad del ser humano, con independencia de su particularidad. El ideal de construir una sociedad plural, más justa, más vivible y deseable para todos, se debe tornar una convicción. Por ello, es pertinente la propuesta de Ha-bermas sobre la capacidad transformadora que tiene la acción comunicativa, pues es la interacción la que tiende puentes dialógicos, al propiciar nuevas maneras de interpretar, crear y recrear relaciones humanas que permitan acercarnos a la comprensión y el respeto conciente del otro, y a interpretar sus acciones, no según modelos abstractos e instrumentales, sino desde sus tradiciones, idiosincrasia, saberes, cosmovisión del mundo y de la vida. Es ella a su vez, la que libera la conciencia de los poderes ideológicos de las hegemonías, que han perpetuado la invisibilidad del otro, la cual es peor que la discriminación, como lo enuncia el profesor Magenzo. (Maguenzo, 1999).

En este contexto, la tarea de la universidad será facilitar la formación de personas autocríticas y autónomas, es decir, de seres morales que opten por el bien colectivo y no sólo por el interés particular. Para eso, debemos instaurar el concepto de persona como tal, como un sujeto moral capaz de discernir y de pensar por sí mismo; de someterse a normas por convicción y no por imposición o por miedo al castigo; de llegar a acuerdos razonables consensuados con el otro, y de hacer de este actuar un modo de vida lleno de posibilidades para la convivencia.

Para que esto sea posible se precisa que la educación haga el puente epistemológicohermenéutico para el desarrollo del razonamiento moral, a partir de la construcción de comunidad justa en la universidad y en todos los espacios de socialización o escenarios de la vida en la polis, pues es allí donde se manifiesta la convivencia real y se vive el pluralismo cultural de nuestra sociedad. Por ello es pertinente entender que la educación como proceso integral y permanente debe trascender las aulas, para evidenciar sus resultados en la sociedad. De ahí la necesidad de hacer de la misma sociedad una comunidad justa en la que se articulen diversos espacios sociales (cátedras, foros en las universidades, ONGs, Juntas de acción comunal, etc.), en los que sea posible el desarrollo del juicio moral de los ciudadanos.

Es pertinente, entonces, optar por lo que afirmábamos al comienzo: educar en la solidaridad, en la convivencia, en la civilidad y en la democracia; en el reconocimiento de la diferencia y la tolerancia.

Los mejores principios de la tolerancia los contempla la Declaración Universal de los Derechos Humanos. Para Colombia el principio fundamental está en el artículo 7 de nuestra Constitución Nacional: «El Estado reconoce y protege la diversidad étnica y cultural de la Nación colombiana» (Constitución Política de Colombia, 1991, 14), lo que en buena ley no genera una contradicción entre una ética mínima y las visiones maximalistas de las culturas. Como lo plantea Victoria Camps: «Sólo cuando existe la discrepancia y la disparidad en el gusto son interesantes la discusión y el diálogo». (Camps, 1997: 99).

Es decir, que de lo que se trata es de encontrar principios que, respetando la pluralidad, puedan ser compartidos por todos los agentes. Ello significa que no serán aceptados aquellos que destruyan la calidad de agentes de los individuos (Garzón Valdez, 1997: 41). 
Hoy es importante que la universidad asuma la función de ayudar a potencializar el desarrollo moral, máxime cuando a ella están ingresando jóvenes de 16 años en los que se presupone un desarrollo moral convencional (en donde el individuo actúa según las normas de su sociedad), con posibilidades de ascender a lo posconvencional o humanista (cuando es capaz de formular principios universales, desde los que critica las normas de su sociedad y en donde el individuo es más maduro cuanto más independiente se sabe de las tramas sociales, cuanto más autónomo es para sellar contratos), esto en el marco de la teoría kohlbegeriana (Reimer, 1997, cap. 1). Pero también es importante tener en cuenta la teoría del desarrollo moral de las mujeres de Gilligan, en donde:

La maduración no consiste en un progreso de la individualización, como en el hombre, sino en un progreso de asumir compasiva y cuidadosamente relaciones que deben ser protegidas por su vulnerabilidad. En el nivel posconvencional la mujer toma conciencia de que ella también es un ser tan digno como los restantes y está dispuesta a romper con las normas convencionales con tal de ser autónoma. La madurez vendrá cuando se sabe responsable de la trama de relaciones en la que ella es una persona fundamental; porque no hay madurez sin autonomía, sin compasión y solidaridad por lo débil y vulnerable». (Cortina, 1993:156).

Se hace esta precisión, pues existen autores que afirman que hay otras maneras, vías o especializaciones en el desarrollo moral, para que el individuo llegue a entender y comprender las situaciones específicas a las que se enfrenta o en las que se encuentra, y de este modo obre moralmente.

Para el fin que persigue la cátedra, es preciso rescatar el debate académico y moral en la universidad, creando una atmósfera de libertad y de justicia desde cada programa, que concientice de la situación de corrupción que se vive en todos los estamentos del país. En estos eventos se debe propiciar la construcción de alternativas de solución, para superar la ruptura que se presenta entre el juicio moral y la acción moral, evidenciada no sólo en la práctica profesional de los docentes (improvisación de la clase, chantaje con la nota, autoritarismo y despotismo frente a los estudiantes, falta de actualización académica, etc.), sino entre los mismos alumnos (copia en exámenes, fraude en trabajos y tesis) y egresados (faltas a la ética profesional y de vida) a más de los vicios administrativos. Es claro, que las actuales prácticas de vida y de trabajo antiéticas no sólo atentan contra normas, reconocidas como universales, sino contra las propias posibilidades de supervivencia del país. Las personas e instituciones que tienen una vida moral como tal, son alicientes para la vida personal y colectiva, y nos plantean el reto de perseguir los ideales éticos para aspirar a una vida mejor.

Una atmósfera moral democrática en la universidad, permitirá el desarrollo de los valores civiles; concientizando a los estudiantes acerca de la importancia y pertinencia para nuestra sociedad (Estado social de derecho) de que lleguen a ser personas autónomas y como tal participen activamente como ciudadanos, haciendo uso público de la razón, para la construcción de un país en donde se pase de la democracia representativa, a la participativa-decisiva (consensuada), en la cual se garanticen la libertad y la igualdad para todos, en el marco de una concepción política de la justicia y de los derechos humanos.

Para que esto llegue a ser posible, se necesita que las personas asuman la democracia como un saber, como una actitud de vida que se refleje en el comportamiento ciudadano. Para educar en moralidad desde la universidad, se precisa la puesta en escena de las teorías éticas, y a partir de ellas confrontar la realidad desde la misma cotidianidad de los individuos, y desde diferentes mediaciones como son por ejemplo, el 
cine, el teatro, la literatura, la misma ciudad, los noticieros, la televisión, etc., pues estas herramientas ayudan a cumplir con el propósito de desafiar el conocimiento y conmover la sensibilidad, para adoptar posturas morales en la toma de decisiones (Blasi, 1989: 331) y, propiciar el paso de una ética heterónoma a una ética autónoma, porque «los logros en el juicio moral deben traducirse a cambios en los patrones de acción, si el desarrollo moral ha de tener algún significado duradero». (Reimer, 1978: 127).

Gracias al reconocimiento de la identidad, en medio de la diversidad, es posible que desde las sesiones y, por qué no, desde las aulas de clase, se co-construya un nuevo diálogo caracterizado por la pluralidad, que permita, como dice Carlos B. Gutiérrez: «...esforzarnos por hacer conscientes nuestros prejuicios, deseos e intereses, a fin de que lo otro deje de ser invisible y se haga valer por sí mismo (...). Tenemos entonces que aprender a respetar al otro y a lo otro» (Gutiérrez, 1997: 83).

A través de esta lente, la asunción de la identidad individual y/o grupal de los proyectos particulares y/o públicos de felicidad o de máximos, no reñirán con la identidad y los proyectos de los otros, pues estarán mediados por la aceptación y el respeto a la diferencia de manera racional y razonable en un mundo global, en donde las costumbres, las diferencias de clase, raciales, religiosas, culturales, políticas, de orientación sexual, de género, de mentalidad o de otro tipo, sean válidas, siempre y cuando, se respete una ética de mínimos y aquellos valores de justicia que salvaguardan el bienestar de la humanidad.

Son estas representaciones colectivas y sociales lo que los teóricos sociales han tratado) de definir como, «estructuras psicosociales intersubjetivas que representan el acervo de conocimientos socialmente disponibles, que se despliegan como formaciones discursivas en el proceso de reconfiguración de las significaciones socio-culturales» (Delgado, 1998: 3).

En la sociedad secular y plural, abierta y globalizada en la que vivimos, unida por las comunicaciones y el mercado, toda la diversidad tiene sentido en la medida que nos sirva para reconocernos en la diferencia, y como puente para recrearnos y re-crear un país, un mundo: "Compartido por plurales y no por uniformes y en donde sea posible enriquecer la convivencia social» (Rey, 1998: 33), con nuevas lecturas y miradas por la simple condición de compartir la misma humanidad.

También, es pertinente resaltar la responsabilidad de los medios y de la educación, para la formación de un nuevo ciudadano que le apueste a un ethos moderno secular y plural, forjando un marco valorativo desde unas nociones claras de justicia, y con el establecimiento de valores normativos colectivos que regulen la vida de lo público en el marco de la civilidad. Esto nos permitirá discernir entre los valores universales que son innegociables, (pues son construidos para la democratización de la sociedad), y el reconocimiento de una ética de máximos, o sea, de aquellos valores culturales que son propios de un individuo, grupo o comunidad, los cuales: «aconsejan qué caminos seguir para alcanzar la felicidad, cómo organizar las distintas metas que una persona se puede proponer, los distintos bienes que puede perseguir para lograr ser feliz» (Camps, 1997: 85).

Es necesario señalar el rol que juegan los espacios de socialización (la familia, la universidad -para nuestro caso-, el barrio, la ciudad, los amigos, el trabajo, la empresa u otros agentes socializadores), pues son ellos los transmisores de valores, de cultura, de ciencia, del desarrollo histórico-social, de tradiciones, de costumbres, de sentires, pero 
también de prejuicios, de exclusiones, de odios, de fundamentalismos, de dogmatismos, etc., y la dimensión educativa y la responsabilidad de los medios que han impuesto y mantenido la ideología dominante, pero que también con su desarrollo han abierto los ojos de los hombres al conocimiento de nuevas culturas u maneras de explicar el mundo, lo que nos obliga a la «transformación de sensibilidades, en los modos de construir imaginarios e identidades.» (Barbero, 1998: 31), a la creación de nuevos referentes morales con base en intereses comunes u no en intereses excluyentes, como se ha visto hasta ahora, es decir, a la construcción de una nueva ética civil.

Este cambio se logrará, en la medida que se den las condiciones para favorecer la cultura de la convivencia respetuosa y solidaria, y la toma de conciencia frente a la participación como ciudadanos en la vida pública; pues es en la vida pública en donde ejercitamos efectivamente la civilidad. Sólo así es posible que los derechos humanos que aparecen en la Constitución Política, que se violan constantemente en el país recordemos los informes desoladores de las Naciones Unidas, de las ONGs, y demás organizaciones defensoras de los Derechos Humanos - de alguna manera empiecen a garantizarse por la acción y el deseo que manifestaron diez millones de colombianos en las marchas de ¡No Más!, y cuando votaron por el Derecho a la Paz, o como afirma certeramente Victoria Camps: «(...) el actuar de acuerdo con unos principios morales es una cuestión no sólo del deber, sino del querer: de voluntad (política e individual) y no sólo de adhesión teórica a unas normas» (Camps, 1996: 35).

\section{Conclusión}

Por eso, desde la Facultad de Educación Física seguiremos insistiendo en el uso de la razón, ya que ella nos impide caer en dogmatismos, en ideas absolutas, en totalitarismos y particularismos, y por el contrario nos posibilita imaginar y construir un mundo más sensato, en donde exista un sujeto moral autónomo y como tal, capaz de discernir por sí mismo y tomar sus propias decisiones; un sujeto que pase de la democracia representativa a la participativa, para que asuma responsablemente sus decisiones $y$ acciones en una sociedad plural, multicultural y compleja como la nuestra.

La Cátedra Abierta y Permanente de Ética, como espacio de discusión y reflexión aspira construir unos valores morales cívicos de convivencia, que permitan construir la concepción de sujeto y de ciudadano, de autonomía, de democracia y de tolerancia para la convivencia ciudadana.

Una concepción ético-política de la justicia es otra de las tareas a realizar desde la cátedra, a partir del marco de la Constitución Política y de los Derechos Humanos, de manera que invite a los participantes a tomar parte activa en la creación de una Sociedad Civil comprometida, ella misma, con la equidad, la igualdad, la solidaridad y el respeto activo frente al otro.

Parece que el mejor epílogo para esta propuesta y que a la vez abre todo un campo de investigación es esta conclusión:

En suma, los tiempos modernos exigen nuevos marcos referenciales, nuevas representaciones colectivas, nuevos valores secularizados que garanticen un mínimo de cohesión social e integración cultural y demandan que esas representaciones colectivas logren permear y cambiar el ethos sociocultural, instalándose en las mentalidades y en los modos de ser $y$ de ver el mundo, en los sentidos comunes, es decir, que se imbriquen con la cultura. Si esto no ocurre, la modernidad no pasa de ser un proceso incompleto porque ésta, como dice Berman, es una forma de experiencia vital, una manera de 
vivir y de asumir las transformaciones inducidas por la modernización económica, tecnológica e instrumental (Uribe de Hincapié, 1998: 11).

\section{Bibliografía}

ACOSTA, Fabián. (1997). “Universo de la Política: pedagogía para lo superior”, Bogotá, Colegio de la Salle.

"Democracia, procedimiento y multitud: la imaginación de las necesidades. Pedagogía para lo superior", Bogotá, Colegio de la Salle.

BARBERO, Jesús Martín (1998). "Experiencia audiovisual y desorden cultural". En: Cultura, medios y sociedad. Jesús Martín Barbero y Fabio López de la Roche. (Comp). Colombia. CES (UN).

BLASI, Augusto (1989). "Las relaciones entre el conocimiento moral y la acción moral: una revisión crítica de la literatura”, Madrid, Editorial Alianza. En: El mundo social en la mente infantil. Elliot Turiel. (Comp.).

CAMPS, Victoria (1996). El malestar de la vida pública, Barcelona, Editorial Grijalbo.

(1997). "El derecho a la diferencia". En: Ética; diversidad cultural León Olive. (Comp.), Bogotá, D.C., F.C.E.

CONSTITUCIÓN POLÍTICA DE COLOMBIA 1994, p.14

CORTINA, Adela (1995). Ética sin moral, Madrid, Editorial Tecnos.

(1993). Ética aplicada; democracia radical Madrid. Editorial Tecnos.

(1996). Ética mínima: introducción a la filosofía práctica, Madrid,

Editorial Tecnos.

DELGADO, Ricardo (1998). "Ética y educación: una mirada desde la perspectiva cultural”. T. I.Bogotá, Artículo Universidad Javeriana.

GARZÓN VALDÉS, Ernesto (1997). "El problema ético de las minorías étnicas". En: Ética y diversidad cultural, Bogotá, D.C., León Olivé, F:C.E. (Comp.).

HABERMAS, Jürgen (1985). "Ética del discurso , Barcelona. En: Conciencia moral; acción comunicativa.

Tecnos.

(1989). Identidades nacionales y potsnacionales, Madrid, Editorial

HOYOS VÁZQUEZ, Guillermo (1997). "Conclusiones generales del seminario ética civil y convivencia ciudadana”, Cali. En: Ética para la convivencia: Memorias.

Siglo del Hombre Editores. IAP. (Comp.)

y URIBE, Ángela (1998). Convergencia entre e’tica y política, Bogotá,

JAMESON, Fredric (1995). Posmodernismo: el postmodernismo o la lógica cultural del capitalismo avanzado, Barcelona, Editorial Paidós Ibérica. 
KANT, Emmanuel (1941). "Respuesta a la pregunta: ¿Qué es la llustración?", México. En: Filosofía de la Historia, Colegio de México. Fondo de Cultura Económico.

KOHLBERG, Lawrence. (1999). "Psicología del desarrollo moral". En: Enfoques y tendencias de la educación moral, Jaime Yañez Canal, (Comp.). Bogotá: Pontificia Universidad Javeriana

LIJPHART, Arend (1989). Democracia en las sociedades plurales: una investigación comparativa, Buenos Aires. Grupo Editor Latinoamericano.

MAGENZO, Abraham (febrero 5 de 1999). "Respuestas del maestro a los retos actuales de América Latina: lección inaugural", Bogotá, Pontificia Universidad Javeriana, Facultad de comunicación. Apuntes manuscritos.

NIETZSCHE, Frederic (1997). La genealogía de la moral, Tratado Primero, Madrid, Alianza Editorial.

OLIVÉ, León. (1997). Ética y diversidad cultural, Bogotá, D. C. Fondo de Cultura Económica.

RAWLS, John (1993). Liberalismo Político, México. Fondo de Cultura Económica.

REIMER, Joseph (1997). "De la discusión moral al gobierno democrático". En: La educación moral según Lawrence Kohlberg, Barcelona, Gedisa, Lawrence Kohlberg, ad alt.

SARTRE, Jean. Paul.(1949). Sobre el humanismo, Buenos Aires, Sur.

URIBE DE HINCAPIÉ, María Teresa (1998). "De la ética en los tiempos modernos o del retorno a las virtudes públicas". En: Ética y Educación: una mirada desde la perspectiva cultural Bogotá, Universidad Javeriana. 